This is a post-print version:

\title{
Dynamic Capabilities and Environmental Sustainability for Emerging Economies' Multinational Enterprises
}

Abstract: The purpose of this study is to enhance our understanding of how macro (country) level dynamic capabilities, such as government environmental policies, legal and market requirements, and technological advances, and micro (firm) -level dynamic capabilities, such as organizational size, culture, and managerial characteristics, are related to emerging economies multinationals' environmantal sustainability policies and practices. Limited studies explore linkages between macro-and micro-level dynamic capabilities and environmental sustainability, which urge emerging economies' multinationals to reconsider their environmental policies and practices in order to compete with enterprises from developed countries. We develop a theoretical framework and offer propositions about the fundamental links between macro and micro dynamic capabilities and emerging economies environmental sustainability efforts. The propositions can be empirically tested in subsequent studies using country-level and firm-level data to examine the interactions between macroand micro-level capabilities, in relation to sustainable polices and procedures, for multinationals in emerging economies.

Keywords: Dynamic capabilities, emerging economies, environmental sustainability, multinational enterprises

Dynamic capabilities (DC) originate from the resource-based view (RBV) of a firm, and these capabilities are linked with "identifiable processes and strategic routines that managers may synthesize to evaluate their resources and integrate them together, generating new applications and value-added strategies" (Eisenhardt and Martin 2000, 1107). As Beske et al. (2014) noted, DC are very difficult to conceptualize and they represent bundles of 
capabilities, not necessarily a single process. Examples of DC include localized business practices linked with macro-and micro-level characteristics, such as culture, service quality, advanced technology, economic environments, social relationships, communication facilities, infrastructure, and government policies. These factors signify that DC are a source through which emerging economies' multinational companies (MNC) conduct their businesses (LaBahn and Harich 1997; Bhaskaran and Sukumaran 2007; Teece 2014; Beske et al. 2014; Williamson 2015). Empirical research shows that DC help enterprises to improve performance and value creation (Naldi et al. 2014).

The fast-paced internationalisation of emerging economies $\mathrm{MNC}$ and their desire to move into and seek strategic resources in international markets (see Cui et al. 2004) provide an opportunity for companies to understand the DC of these enterprises, and suggest guidance for other MNC embarking upon this transformational journey. In the process of investing abroad, MNC from emerging economies not only seek resources, but they also share their expertise arising from 'location-specific specialities at home' (Luo and Tung 2007). Furthermore, emerging economies demonstrate a unique institutional and legal environment, and theories developed in the Western world may not unanimously be applied to these economies (Chakrabarty and Wang 2012; Xu and Meyer 2013). Emerging economies MNC differ significantly from their counterparts in developed countries, in terms of size, structures, operations and managerial characteristics (Kotabe et al. 2011). However, like developed markets, emerging economies also share some similar characteristics (Meyer and Peng 2016), and therefore it can provide an interesting context to explore the relationship between DC rooted in macro-and micro levels and sustainability practices. Increasingly, academics and practitioners have started focusing on emerging economies MNC. For example, Jormanainen and Koveshnikov (2012) carried out a content analysis of articles on emerging economies MNC in top tier management journals published between 2000 and 2010. They found that 
emerging economies MNC have substantially increased during this reporting period, highlighting the importance of this research area in the academic literature.

The concepts of sustainability and sustainable operations determined by DC are integral components of corporate strategies. The need to explore the linkages between DC and environmental sustainability is driving organizations to reconsider their operations and strategies (Sölvell and Zander 1995; Nidumolu et al. 2009; Hall and Howe 2012; Beske et al. 2014; Teece 2014; Gruchmann and Seuring 2018; Chen et al. 2019). Further, Atkinson (2000) and Pagell and Wu (2009) argued that sustainable DC are the ones that drive firms to achieve multi-dimensional performance, namely environmental, financial and social sustainability. This means that regulations relating to the outcomes of emerging economies' MNC are partly driven by the sustainable practices of organizations. Thus, sustainability is affected by overall DC (i.e., both macro-and micro-level capabilities). Such capabilities may result in financial and non-financial benefits, such as lower cost, better product outcomes and enhanced service quality, significant waste reduction, efficient energy consumption, and, most importantly, environmental protection/adoptation (Hall and Howe 2012; Parboteeah et al. 2012; Williamson 2015).

Employees (e.g., managers) and organizational practices are considered to be microlevel DC (Teece 2007). In other words, these capabilities represent the cognitive abilities of corporate managers who control MNC (Bhaskaran and Sukumaran 2007; Zhou and Li 2010; Helfat and Peteraf 2015). For example: "the capability for sensing opportunities and threats can be developed and improved through both the cognitive and creative capacities of individuals and some organizational processes such as research and development activities" (Molina-Azorín 2014, 110). At a firm-level, it includes human DC (e.g., human resource expertise), physical (e.g., firms' geographical location and specialized equipment) and 
organizational, strong internal corporate governance and control, which can be utilized by implementing value-enhancing corporate strategies (Barney 1986, cited in, Eisenhardt and Martin 2000, 1107). The ability for a firm and its employees to be innovative and entrepreneurial can help in sensing and seeking out new opportunities in the wider business ecosystem ahead of the competition, thus, encompassing the element of both macro-and micro-level capabilities (Teece 2007). In summary, DC are "the strategic routines by which firms achieve new resource configurations as markets emerge, collide, split, evolve, and die" (Eisenhardt and Martin 2000, 1107).

Macro-level DC are represented by external institutional factors, such as government policies and regulations, stakeholders, market requirements and the external economic and business environments in which firms operates. How well a firm performs in a dynamic business environment is dictated by a combination of both macro-and micro dynamic capability factors (Porter 1985). For instance, Adner and Kapoor (2010) described the Airbus A380 case study. They noted the challenges faced by Airbus in the pursuit of product innovation, did not reside just within the focal firm itself, but extended into the firm's wider ecosystem, beyond the dyad. Thus, in order to obtain a holistic view of how sustainable DC affect the performance of emerging economies' MNC, there is a need to assess both macroand micro-level factors that straddle sustainable practices. Furthermore, macro DC may be argued by some simply as factors that influence a firm's DC/performance. Yet, from a system's perspective, a firm exists within a wider business ecosystem and macro DC form part of the overall system of 'capabilities,' which a firm can possess and leverage to improve sustainable performance. For instance, not all emerging MNC will leverage or take advantage of government policies/incentives/taxes and local markets to drive sustainable improvement, particularly if they are SMEs trading locally compared to a large company trading globally 
within the same country context (Raţiu and Mortan 2014). Thus, a firm's micro DC may influence how well it leverages the macro DC and vice versa.

Micro-level DC are analyzed here at both the individual and the organization levels, which is an extension of the RBV theory. The issue with looking at micro-level DC in isolation is that it does not offer an explanation as to why certain organizations sustain a competitive advantage in dynamic environments and others do not, even when they possess similar resources (Yassien and Jordan 2015). Thus, there is a need to address both micro and macro- level DC simultaneously to understand how they interrelate to achieve environmental sustainability. Yet, very little research has investigated the impact of both micro and macro DC. For instance, many studies have explored only micro-level DC, such as individuals and organizations (Teece 2007; Eisenhardt et al. 2010; Hodgkinson and Healey 2011; Argote and Ren 2012; Teece 2012), however, there is a need to understand both, if emerging multinational enterprises want to succeed in entering new markets.

MNC enterprises have the capacity and resources to effectively respond to environmental factors (Rugman 1985). For instance, by responding to pressures from regulatory bodies (Bengtsson 1993) or they may approach it more symbolically in legitimizing corporate actions (Kuznetsov and Kuznetsova 2012). Despite the increasing awareness about environmental sustainability in the last couple of decades, the subject area is becoming a mainstream focus in the field of business and management (EMAS Board 2011; Hall and Howe 2012; Dooley 2017). For example, more than 223,149 companies from 159 countries had registered with the Environment Management System Certification (i.e., ISO 4001) by 2010 (ISO 2010). Similarly, the number of registered companies' for EcoManagement and Auditing Scheme (EMAS) doubled to 4,659 between 1997 and 2011 (EMAS Board 2011). However, Marcus and Anderson (2006) noted that, while DC do not 
necessarily result in improved performance of environmental management systems, they can result in improved performance of the overall supply chain. A recent study by Shaw et al. (2016) concluded that ISO 14001 adoption was evident and growing in developing nations, such as Thailand, because it was seen as a pre-requisite for trading with developed nations.

Beske et al. (2014) proposed eight distinctive capabilities: (1) knowledge assessment; (2) knowledge acquisition; (3) ability development; (4) search, selection and integration of partners; (5) supply chain foundations; (6) produce and process development; (7) relationship management; and (8) reflexive controls. They proposed that if a capability, such as knowledge acquisition, helps to integrate new knowledge into the knowledge base of a firm, which results in a change or adoptation to that firm within its wider supply chain, then it can be considered a DC. However, fundamental questions still need to be addressed. Firstly, much of the extant research requires more in-depth reviews. Secondly, it is acknowledged that companies need to focus on environmental issues under the wider umbrella of corporate social responsibility (CSR). Yet, the literature addressing the key macro-and micro DC that strengthen environmental sustainability has not articulated the missing links between macroand micro level capabilities and environmental performance/sustainability (Thompson and Cavaleri 2010; Beske et al. 2014; Williamson 2015; Dooley 2017; Chen et al. 2019). Thirdly, the literature in this area has focused predominantly on MNC from the Western world and not emerging economies. Thus, this research is timely as it explores the interaction between DC and the sustainable and CSR practices of these emerging economies MNC.

Further, progress in the area of environmental sustainability has been gradual in practice, particularly in the context of developing economies (Pagell and Wu 2009; Zhou and Li 2010; Williamson 2015). Although few studies, with the exception of Park et al. (2007), Beske et al. (2014), and Williamson (2015), have investigated the relationship between DC 
and sustainability dimensions, the missing links remain between macro-and micro level DC and environmental sustainability. To cober for this gap in the literature we develop a conceptual framework and research agenda, from the existing literature, that can be used in understanding the relationship between DC and sustainability practices in the context of emerging economies MNC. We explore the interaction between macro-and micro-level DC and their perceived impact on the environmental practices of emerging economies MNC. We propose six propositions that could be tested in subsequent empirical research, and the conclusions arising from this study are presented in the final section of this article.

\section{THEORETICAL FRAMEWORK AND PROPOSITIONS}

DC Macro-level DC external factors (e.g., government policy and regulations towards sustainability, the use of modern technology to reduce harmful emissions, market requirements and economic environments), can directly or indirectly influence micro-level DC and environmental sustainability. Both institutional and stakeholder theories play an influential role in understanding how firms respond to their external business environments. For instance, although many environmental management standards are voluntary, many organizations are coerced or encouraged to adopt them by suppliers, customers, and, in some cases, through government tax incentives (Shaw et al. 2016). In other contexts, organizations may feel that they need to conform or simply mimic the action of competitors (DiMaggio and Powell 1983; Shaw et al. 2016).

Micro-capabilities, such as the organizations' structure/size, environmental policy, management characteristics (board independence, culture, gender diversity, amongst others) and the types of coordination ${ }^{1}$ for their environmental effectiveness, also affect

\footnotetext{
${ }^{1}$ With the introduction of corporate governance regulations around the world, many companies have now established committees that look after the corporate social responsibility and sustainability related affairs of an
} 
environmental sustainability, leading to operational, financial, social and strategic advantages for emerging economies' MNC. The implementation of firm-level (micro) DC may yield many benefits, but also need resources, extra time, financial costs and managerial coordination efforts. RBV theory and its extension, provides a useful lens through which the micro DC of emerging economies' MNC can be understood (Barney et al. 2011; Hart and Dowell 2011). This is because a firm's resources and capabilities, such as employees, leadership teams and business culture, play an important role in the successful implementation of environmental practices, and ultimately enhance performance through triple-bottom-line (Elkington 2004).

Teece (2007) noted that in fast moving business environments, dominated by various factors, such as global competition and differing market conditions, understanding the success of a firm cannot be just limited to a macro or micro view of DC, but how firms harness both. Further, the literature on the relationship between DC and environmental sustainability reports has conflicting results. For instance, Teece et al. (2007) argued that DC could be a source of sustainable advantage, while Eisenhardt and Martin (2000) argued that it could be a source of sustainable disadvantage as these [dynamic] capabilities are 'itself not stable'. Peteraf et al. (2013) suggested that these two contrasting paradigms coexist with some logical assumptions and researchers can use these assumptions from both perspectives in developing an integrated framework of DC. Figure 1 below describes the interrelationship between macro-level (i.e., country-level) and micro-level (i.e., firm level) DC. The interaction between micro and micro-level DC have positive implications for organizational environmental sustainability. These micro-macro level interactions also result in firm-level operational, financial, social and strategic advantages.. Further examples of the interaction to link different dynamic capabilities so better environmental results can be obtained. 
between macro-micro level capabilities are presented in the following sections (also shown in Figure 1).

\section{Insert Figure 1 about here}

Macro-level dynamic capabilities (DC)

Government policies, quality indicators, legal requirements and technology

Macro-level DC are shaped by government policies, regulations and practices that support multinational enterprises' efforts to promote their representation. For instance, the Malaysian government has introduced an economic programme aimed at strengthening Malays' MNCs representation in the country. Substantial preferences in business, education, housing, and employment have been given to Malays. Preferential contracts have also been given to Malays, and, in-turn, political, economic and social changes have been seen in Malaysian macro-level DC. This new era has created competition for Chinese MNC, which have also made efforts to enter into partnerships with foreign enterprises. This development has challenged the level of DC for Chinese enterprises, competing with local Malaysian MNC (Bhaskaran and Sukumaran 2007).

Government policies direct firms towards environmental leadership and ultimately enable coordination between parties (such as companies, governments and other regulatory agencies), which put cooperative efforts in place to achieve environmental sustainability. For example, the government of Canada developed a variety of new supporting policies that ultimately have resulted in a joint Commission on Resources and Environment (CORE), which help enterprises to integrate sustainability guidelines into their environmental business strategies. The independent commission crystalized a provincial strategy that focuses on coordination within and between government departments to further develop environmental 
sustainability. Similar developments are made for emerging economies' multinational enterprises and represent examples of how institutional pressure is shaping these nations' landscapes around environment sustainability (Sarkis et al. 2011). However, such developments need government-level efforts to strengthen macro-level DC for MNC enterprises and their links with environmental sustainability practices.

Switzerland, Latvia, Norway, Luxembourg and Costa Rica are leading in terms of being environmentlly friendly compared to other nations This is because they have achieved better results on key environment performance measures (EPI, 2012). These results achieved in the context of developed markets suggest that middle-income countries like Latvia (GDP $\$ 12,938$ per capita) and Costa Rica (GDP \$19, 238 per capita) can potentially achieve remarkable environmental outcomes which implies that, although generating income and wealth creation is important, good environmental policies and practices are the key determinants of success. Additionally, the policies of leading countries do not only focus on internal-governmental coordination, but also working together with industries and environmentalists that play a key role in achieving environmental sustainability (Bachmann 2003; EPI 2012; Graafland and Smid 2017).

The Environmental Performance Index (EPI) report concludes that environmental challenges and issues vary between countries. The results from EPI recommends using a local approach, namely, the identification of local problems and finding solutions accordingly. The EPI report also finds that developing countries' governments fail to implement a systematic processes to verify environmental data, such as water quality, waste management, recycling and toxic exposures (EPI 2012; Graafland and Smid 2017; Liang and Liu 2017). These findings raise concerns about the quality of regulations, governance and the accuracy of available data in the area of environmental sustainability. 
It is thus important, for government departments to introduce stringent environmental laws and regulations that can lead towards environmental certification schemes, which also require enterprises to incorporate environmentally friendly regulations and practices, as an integral part of their corporate strategies. Gabzdylova et al. (2009) and Shaw et al. (2016) found that government regulations are key drivers for adopting sustainable practices and need to be mandatory rather than voluntary in order to improve the environmental practices. The survey conducted by Collins et al. (2010) showed that companies are not strongly compelled to adopt sustainable practices, particularly in developing countries (Liang and Liu 2017).

Sustainable and environmental practices are fundamentally embedded in the environmental laws that vary significantly across countries, regions and even cities. Thus, companies that are governed by better environmental regulations, and comply fully with sustainable practices, may yield considerable financial and non-financial advantages over competing firms (Nidumolu et al. 2009; Liang and Liu 2017). Thus, the institutional pressure from government is key to the successful implementation of environmental sustainability within the wider macro business environment.

\section{Market requirements}

It is pivotal for companies to consider new market requirements and expectations from various stakeholders (e.g., customers, consumers and media), who also impact enterprises' environmental strategies. For example, the media is an important source of sustainability awareness for consumers who can reward/punish compliant/non-compliant firms. Markets are growing with environmentally informed consumers and customers, and these stakeholders 
demand factual evidence for environmental support from and compliance by multinational enterprises. Customers are also willing to pay a premium for environmental certification programs (Grolleau et al. 2007).

Modern consumers give significant consideration to environmentally-friendly MNC. For instance, enterprises, such as the Carbon Trust in the UK, use carbon labels and other media to create consumer awareness about environmental sustainability, which is one of the reasons that today's green consumers demand greener products and services. Thus, pressure from customers are key drivers, as they raise concerns about product environmental quality and regulations (Gabzdylova et al. 2009).

Considering customers' and consumers' preferences can help to build the corporate image and reputation. In turn, this makes the trading between the domestic market and foreign markets much easier (Shaw et al. 2016). Ultimately, such considerations provide a greater ability to work with superior partners in the industry (Gabzdylova et al. 2009). Particularly, the policies and focus of leading overseas markets have significantly shifted towards environmental sustainability. For example, some retailers have recently developed 'Certification Schemes' such as EurepGAP and GlobalGAP that assures conformity with environmental and labor requirements and product safety for consumers. Further, many large MNC voluntararily report their environmental performance through schemes, such as the Global Reporting Initiative (GRI), as a way to showcase their environmental credibility. For instance, Tesco PLC, having 30.7\% market share of the UK's retail sector (and being one of the $4^{\text {th }}$ largest world retailers), has recently developed a certificate scheme, called Nature Choice. This certification not only establishes firm-level environmental standards but also specifies size, taste, shelf life and a variety of other product related attributes. In fact, it does not matter whether Tesco's suppliers are from developed countries or emerging economies, 
they have to comply with the terms and conditions required by the certification (Saunders et al. 2010).

Market requirements also demand environmental-friendly product policies, such as sustainable packaging, labelling and product development using recycled content.. Such policies also improve the reputation and legitimacy of multinational organizations. These factors, linked with manufacturing, production and reverse supply chains, attract and retain business partners, which, in turn, help to increase a firm's market share. (Sharma et al. 2010). MacRae et al. (2012) argued that sustainable packaging and labelling reduce costs and promote recycling and energy saving. Such practices not only help in protecting the environment, but may also result in enhanced corporate disclosure relating to environmental issues, i.e. use of chemicals, nutrition, and health and safety, and issues concerning animal welfare. However, it is unlikely that manufacturers would voluntarily label their products with information and data about policies that are environmentally harmful. Thus, effective macro-level (country-level) environmental legislations can play a crucial role in coercing firms to comply with health and safety as well as with the environmental standards (Tobler et al. 2011; MacRae et al. 2012).

Product labelling should also include transportation modes and distance traveled, as they heavily affect environmental sustainability. Such information helps consumers to purchase local products and reduce harmful environmental impacts (Tobler et al. 2011). For instance, locally produced vegetables in the Netherlands require $6 \mathrm{MJ}$ per $\mathrm{kg}$. However the same quantity of vegetables transported from Africa to Netherlands require $88 \mathrm{MJ}$ (Tobler et al. 2011). A recent survey shows that environmently-focused consumers consider transportation distances and prefer to buy products local than global (Tobler et al. 2011). 
When entering a new market, a firm is able to develop 'difficult to replicate' DC, which can be used to continuously harness, create, extend, upgrade and protect their asset base (Teece 2007, 1319). Teece (2007) disaggregates this into three main components: (1) to sense and shape opportunities and threats; (2) to seize opportunities; and (3) to maintain competitiveness through enhancing, combining, protecting, and when necessary, reconfiguring the business enterprise's intangible and tangible assets. From a theoretical perspective, such ability requires the co-ordination of not only macro but also micro DCto realize these opportunities/threats and achieve environmental sustainability.

In summary, pressure by stakeholder, such as customers, suppliers and final consumers, are the key parameters that drive to build DC that are linked with sustainable practices. The literature in this area shows that consumers often have insufficient knowledge to assess environmentally-friendly products. Additionally, governments' pressure often fail to enforce stringent regulations relating to packaging and labelling. Governments can develop and enforce environmental policies, and can create environmental awareness, which can force MNC to build their DC regarding environmentallyfriendly practices (Tobler et al. 2011; MacRae et al. 2012; Mikalef and Adamantia 2017). However, it is the co-ordination efforts, both at the macro and micro level, which together have a synergistic effect in developing difficult-to-replicate DC.

For instance, at a macro level companies are under immense pressure from shareholders in the stock market, as well in the consumer/product market, to demonstrate their sustainable credentials. Large global companies, like Clariant, a world leader in specialty chemicals, have to demonstrate their green compliance to shareholders by being part of programs such as the Dow Jones Sustainability Index or the FTSE Good Index (Clariant 2017). However, at a firm level, companies may also set-up voluntary disclosure 
committees, corporate social responsibility (CSR)/ sustainability committees, or even appoint sustainability directors, to signal their focus on and commitment to business ethics and sustainability. Clariant, who have a dedicated Vice President for Sustanability, have integrated sustainability programs across and within its operations, from the corporate strategy down to processes and product development to become number one on the Dow Jones Sustainability Index. Together, the interaction between such external enforcement and internal commitment may positively affect a firm's contribution to CSR activities.

\section{Economic capability}

The key factors that strengthen the economic capability of a country could include high income and better exports, contributing to gross domestic product (GDP)(Van and O'Brien , 2019). Consequently, such economic activities result in higher demand for goods and services, resulting in increased need for imports and exports, which increases the carbon footprint of supply chains (local versus global) .

In building economic capabilities, governments may develop different legislations for firms according to their size, structures, and operations. For example, government often places direct and indirect costs, such as social contributions of employers, taxation and compliance costs, to meet legal requirements. In addition, the requirements are often very stringent for larger firms compared to requirements for smaller firms with limited resources. Enterprises may face challenges to meet such costs, as a one-size-fits-all approach may not be suitable in promoting environmental and sustainability related practices. Therefore, to avoid the risk of non-compliance and subsequently execution, governments may develop supporting policies and tax incentives that assist enterprises to overcome firm-specific disadvantages in meeting environmental compliance. 
The complexity of government procedures and regulations, shortage of labor, unemployment and competitive hostility also affect enterprises that, in turn, affect DC. The development of economic institutions, such as supporting infrastructures, banks and education systems, is important to the building of macro-level economic capabilities (Smallbone and Welter 2001).

To measure the performance of macro capabilities, Elekda (2008) recommend three indicators, namely, interest rates, oil prices and GDP. Among these indicators, GDP is widely used in the academic literature (Elekda 2008). However, GDP only considers the total market production and it cannot be used to measure the overall welfare of a cournty, so it can provide misleading signals to policy makers. A recommendation is to consider real household income, household consumption and net national income that are closely associated with household living standards that are linked with macro-capabilities. It is also suggested that measures of income, consumption and wealth should be accompanied by those indicators that imitate their distribution. Additionally, healthy competition in targeted markets also provides opportunities that could significantly influence DC and relative policies (Sölvell and Zander 1995; Zhiwei et al. 2011; Pisano 2016).

Based on the above discussion, we present the following propositions that can be tested in subsequent research:

Proposition 1: There is a positive relationship between key macro-level dynamic capabilities (DC) and environmental sustainability.

Proposition 2: There is a positive relationship between key macro-level dynamic capabilities (DC) and micro-level dynamic capabilities (DC).

Micro-level dynamic capabilities (DC) 
Large MNC that have grasped commercial benefits from environmental sustainability include Unilever and Proctor and Gamble. These companies consider the natural environment as a central concern to customers, shareholders and staff (Redclift 2005). Such big companies can easily afford environmental certification schemes, which could be costly for emerging economies' MNC. For example, an average environmental management program could cost around $€ 150,000$. Thus, the probability of registering and implementing an environmental certification scheme is associated with larger firms (Grolleau et al. 2007).

In fact, there is no such enterprise that negatively impacts social and natural systems (i.e., environmental sustainability). However, some companies and industry sectors may do better than others in achieving environmental sustainability (Pagell and Wu 2009). For example, the damage to the environment [air emissions] in the electricity sector decreased by nearly 50\% between 1987 and 1994. Similarly, in the agriculture sector, a significant reduction has been observed in $\mathrm{PM}_{10}$; however, $\mathrm{CO}_{2}$ and $\mathrm{SO}_{2}$ have gradually increased in agriculture industry (Atkinson 2000). Simnett et al. (2009) believed that companies in utilities, finance and mining are more likely to focus on the assurance of their sustainability reports. ${ }^{2}$ Pagell and $\mathrm{Wu}(2009)$ also scrutinized ten sustainable enterprises, namely, Snack Food, Food and Beverage, Pizza Restaurants, Cleaning Products, Forest and Wood Products, Electric Scraps, Paper Products, Lighting Products, Building Renovation and IT Equipment. The findings show that majority of these organizations mainly focused on: (1) employees' training about environmental sustainability; (2) linking their corporate strategy and

\footnotetext{
${ }^{2}$ Sustainability assurance is very similar to an audit where the social and environmental policies/activities of an organization are examined by an independent external consulting/auditing firm. The assurance certificates issued by the consulting/auditing firm give some assurance to investors and other stakeholders that the social and environmental activities of an organization are independently verified and hence such disclosure can be trusted. Currently, the Big Four auditing firms frequently issue assurance certificates for large and listed companies.
} 
performance measurement systems to sustainable practices; (3) sustainability issues as part of their daily conversations; (4) developing guidelines for acquiring certifications; (5) transportation and production efficiency; (6) the use of advance technology; (7) the integration of sustainability into the entire organization; and (8) building micro-level DC by emphasizing internal operations (Redclift 2005; Pagell and Wu 2009).

Gabzdylova et al. (2009) believe that firm size seems to be an important factor in the adoption of environmental practices. In support, Gallo and Christensen (2011) found that large enterprises with sufficient manpower and funds were better off in responding to sustainability related regulations. This can be explained by the RBV, suggesting that, compared to smal organizations, large organizations have access to greater resources such as finance, people, systems and processes that increase their ability and capability to implement environmental sustainability practices (Nawrocka et al. 2009). Research also showed that a firm's ownership structure (public or private) is strongly related to environmental sustainable practices. It has also been observed that innovative enterprises are more likely to be successful in employing environmental sustainability initiatives (Gallo and Christensen 2011; Arora and Hartley 2017).

Firm-level internal control systems could significantly influence a firm's corporate social responsibility practices. Almost every country has now implemented a formal corporate governance code. A corporate governance code includes guidelines and best practices, and the board of directors is required to comply with such national-level regulations and guidelines in order to enhance the accountability and transparency of its organizations (Jamali et al. 2008). If governance regulations are implemented in an effective way, they can contribute to stakeholder activities (e.g., corporate social responsibility initiatives) to make firms more visible and to preserve corporate legitimacy. We, therefore, 
expect a positive relationship between a firm's internal governance structure and environmental sustainability.

\section{Management characteristics and coordination efforts}

Managers' relevant education, past experience and environmental support, traditional measures, modern preventive systems can improve the performance of natural environment that reflects an enterprise's environmental policy (Grolleau et al. 2007). In particular, top management perceptions and support, such as employees' empowerment, rewards, environmental training and frequent internal and external coordination efforts, could also affect sustainable practices. Top management especially reflects micro-level policies and corporate culture. It is important therefore to match such factors to encourage the implementation of environmental practices (Bachmann 2003; Akhtar et al. 2017). Moreover, a corporate strategy that encourages employees to work from home may also help in reducing energy usage, travel costs and time (Nidumolu et al. 2009). In support, the study also found that one-tenth of surveyed companies had $21-50 \%$ of employees who worked from home using telecommunication and other online tools, and, as a result these enterprises have saved $\$ 550-700$ million dollars, and their production capacity improved by 10-20\%. Consequently, employees' job satisfaction level increased significantly (Nidumolu et al. 2009). Gabzdylova et al. (2009) and Collins et al. (2010) also believe that corporate values, employees' commitment, satisfaction and the belief of top management to embrace corporate social responsibility initiatives are the fundamental firm-specific factors that drive environmental sustainability.

Additionally, the efficiency relating to environmental sustainability is derived from working together with business partners to develop eco-friendly raw materials, production and waste reduction. Co-ordination efforts are important and help in improving corporate 
image and legitimacy, reducing associated litigation costs arising from non-compliance with environmental laws. In this way, key business coordinators can play a vital role in promoting awareness and developing collaborations with other organizations to protect the environment. For example, Wal-Mart develops guidelines for its suppliers (including those in emerging markets), and together with their suppliers, they set out targets to increase energy efficiency by $25 \%$ and reduce packaging cost by $5 \%$ in few years (Nidumolu et al. 2009). Concisely, the coordinated efforts between participant companies, government and regulation agencies can lead to environmental sustainability. These arguments lead to the following propositions:

\begin{abstract}
Proposition3: There is a positive relationship between key micro-level dynamic capabilities (DC) and environmental sustainability.
\end{abstract}

Proposition 4: There is a positive relationship between the coordination efforts (i.e. linking macro-and micro-level dynamic capabilities (DC) and coordination efforts within departments and with supply chain partners) and environmental sustainability.

Environmental Sustainability, advantages and disadvantages

In 1987, the concept of sustainability was defined as "development that meets the needs of the present without compromising the ability of future generations to meet their own needs" (Redclift 1993, 8). The three dimensions of sustainability (i.e., environmental, economic, and social) can be contradictory, as well as complimentary with each other (Mollenkopf et al. 2010). For example, if a number of developed economies agree on promoting environmental sustainability, it may not necessarily be equally applicable to those emerging economies that 
seek more natural resources' exploration and wealth (e.g., China, India). Thus, definitions of sustainability are still vague, broad in scope and can mean different things to different countries (Atkinson 2000; Pagell and Wu 2009). Furthermore, cultural and political changes such as globalization, de-globalization (e.g., the UK leaving the EU and the US foreign policies) and ongoing wars in countries such as Afghanistan and Iraq, have increased the number of challenges for the global environmental development and sustainability (Redclift 2005; Casey 2017).

As discussed in the preceding section (Hall and Howe 2012; Parboteeah et al. 2012), emerging markets $\mathrm{MNC}$ ' are likely to enjoy the financial and non-financial benefits associated with environmental sustainability. The potential advantages include cost savings related to waste reduction, material, health and safety and labor. Saving these costs generates additional revenue that enables emerging economies MNC to expand their existing business models into overseas markets. There is obviously no substitute to sustainability, although some CEOs have raised concerns that embedding sustainability in each aspect of the business model would be too costly for their organizations. They also assert that sustainable production demands new technology and processes that increase immediate costs, and consumers may not be willing to pay extra for eco-products, although some researchers may argue against this statement (e.g., Grolleau et al. 2007). That is why top management often divorce environmental sustainability from their core business policy and strategies (Nidumolu et al. 2009).

The key advantages of environmental sustainability include improvement in operational performance (i.e., increasing profit by cost savings on energy usage, waste management, water usage, chemicals and transportation cost reduction, social outcomes (i.e., stakeholder trust and satisfaction), strategic benefits (i.e., better market access, greater 
understanding of the modern business preferences, brand recognition, joint decision-making, effective regulations and benchmarking guidelines) (Carter and Rogers 2008; Collins et al. 2010; Hall and Howe 2012; Parboteeah et al. 2012). The disadvantages are; membership fee, extra time to fill in the forms and to follow burdensome bureaucratic procedures, having extra costs related to the adoption of new technology, and the cost relating to the environmental audit and assurance (Grolleau et al. 2007; Nidumolu et al. 2009; Collins et al. 2010). We offer the following proposition:

\section{Proposition 5: Environmental sustainability results in more advantages than disadvantages, when these advantages are supported by macro-and micro-level dynamic capabilities (DC).}

\section{CONCLUSION AND FUTURE RESEARCH}

Empirical studies have extensively debated the determinants of corporate social responsibility and its impact on corporate performance and market valuation. Although the concept of environmental sustainability was coined a few decades ago, not enough research has been conducted to investigate the key linkages between DC and environmental sustainability, particularly in the context of emerging economies MNC. Within the framework of DC, the major macro-capabilities that directly and indirectly affect environmental sustainability, include government policies, legal and market requirements, technological advances and economic capacities. These factors are also associated with MNC' micro-level capabilities, such as management characteristics, environmental strategies, operations, and coordination efforts. We argue that the coordinated efforts by those players involved in promoting environmental sustainability (i.e., government, companies, supply chain partners and regulatory agencies) could significantly affect firm-level initiatives (voluntary and 
mandatory) relating to environmental sustainability. We suggest that future studies should explore and test the interaction between country-level and firm-level DC.

The propositions presented in this research can be empirically tested using secondary data on DC and environmental sustainability. It thus provides a conceptual framework for further empirical research and for the testing of the propositions in a case study or industry setting through surveys or using panel data already available on different databases. We also suggest to utilize the interaction between firm-level ESG (environmental, social and governance) data and the country-level indicators of institutional quality (rule of law and judicial efficiency) to test the propositions presented in this article. We also suggest that there is no harm in using a 'cherry picking' or benchmarking approach, whereby emerging economies MNC can benefit from best practices used by their competing firms in developed countries. This might help them to take a proactive approach in order to tackle environmental issues (Scherr 2007; EPI 2012; Akhtar et al. 2012). We also argue that informal norms distributed through vibrant media (social, print, and electronic media) could also be used as a tool to reward/punish compliant and non-compliant firms in the area of environmental sustainability. We suggest stringent environmental regulations for companies operating in emerging economies, consequently substantial fines and penalties can be implemented for those companies violating environmental regulations. We also suggest that compliance with environmental programs should be required as a 'listing requirement' on all major stock exchanges around the world, so that firms can be de-listed from stock markets in the event of non-compliance with environmental regulations.

\section{REFERENCES}


Adner, R. and R. Kapoor. 2010. "Value Creation in Innovation Ecosystems: How the Structure of Technological Interdependence Affects Firm Performance in New Technology Generations." Strategic Management Journal 31 (3): 306-333.

Akhtar, P., N. E. Marr, and E. Garnevska. 2012. "Chain Coordinators and their Role in Selected Agri-food Supply Chains: Lessons from Pakistan, New Zealand and United Kingdom.” Food Chain 2 (1): 104-116.

Akhtar, P., Z. Khan, J. G. Frynas, Y. K. Tse, and R. Rao-Nicholson. 2017. "Essential Micro-Foundations for Contemporary Business Operations: Top Management Tangible Competencies, Relationship-based Business Networks and Environmental Sustainability." British Journal of Management 29 (1):43-62.

Argote, L., and Y. Ren. 2012. "Transactive Memory Systems: A Micro Foundation of DC." Journal of Management Studies 49 (8): 1375-1382.

Arora, A. S., and N. Hartley. 2017. "Sustainability, Institutions, and Internationalization in Emerging Markets: Role of Sustainable Innovation for Sustainable World Development." International Journal of Emerging Markets 12 (1): 920-926.

Atkinson, G. 2000. "Measuring Corporate Sustainability.” Journal of Environmental Planning and Management 43 (2): 235-252.

Bachmann, R. 2003. “The Coordination of Relations across Organizational Boundaries.” International Studies of Management \& Organization 33 (2): 7-21.

Barney, J. B., D.J. Ketchen, and M. Wright. 2011. "The Future of Resource-based theory: Revitalization or Decline?” Journal of Management 37 (5): 1299-1315. 
Bhaskaran, S., and N. Sukumaran. 2007. "National Culture, Dynamic Capabilities and Management Practices: Consequential Relationships?" Cross Cultural Management: An International Journal 14 (1): 54-67.

Bengtsson, L. 1993. “Governmental Markets, Regulations, and Hierarchies: Building Trust in the Face of Nationalization." International Studies of Management \& Organization, 23 (1): 47-68.

Beske, P., A. Land, and S. Seuring. 2014. "Sustainable Supply Chain Management Practices and Dynamic Capabilities in the Food Industry: A Critical Analysis of the Literature." International Journal of Production Economics 152 (S): 131-143.

Casey, C. A. 2017. "De-globalization and the Disintegration of the European News System" 1918-34. Journal of Contemporary History 53 (2): 267-291.

Carter, C. and D. Rogers. 2008. "A Framework of Sustainable Supply Chain Management: Moving Toward New Theory." International Journal of Physical Distribution and Logistics Management 38 (5): 360-387.

Chakrabarty, S. and L. Wang. 2012. "The Long-term Sustenance of Sustainability Practices in MNCs: A Dynamic Capabilities Perspective of the Role of R\&D and Internationalization." Journal of Business Ethics 110 (2): 205-217.

Chen, I. S. N., P. K.O. Fung and S. S. M. Yuen. 2019. "Dynamic Capabilities of Logistics Service Providers: Antecedents and Performance Implications.” Asia Pacific Journal of Marketing and Logistics 31 (4): 1058-1075. 
Clariant 2007. Clariant achieves best-in-class rankings in 2017 dow jones sustainability index, available at: https://www.clariant.com/en/Corporate/News/2017/09/Clariant-achievesbestinclass-rankings-in-2017-Dow-Jones-Sustainability-Index (accessed 22 October 2019).

Collins, E, Roper, J and Lawrence, S. 2010. "Sustainability practices: Trends in New Zealand businesses.” Business Strategy and the Environment 19(8): 479-494.

Cui, L., Meyer, K.E. and Hu, H.W. 2014. 'What Drives Firms' Intent to Seek Strategic Assets by Foreign Direct Investment? A Study of Emerging Economy Firms.” Journal of World Business, 49(4): 488-501.

DaiDiMaggio, Paul, and Walter W. Powell, 1983. “The Iron Cage Revisited: Collective Rationality and Institutional Isomorphism in Organizational Fields.” American Sociological Review 48 (2):147-160.

Dooley, K. 2017. Value Chain Systemicity: "Promoting Organizational Creativity and Environmental Sustainability in Low Velocity Industries.” Journal of Cleaner Production, 140: 1903-1913.

Eisenhardt, K.M. and Martin, J.A. 2000. "Dynamic Capabilities: What are They? Strategic Management Journal.” 21(10): 1105-1121.

Eisenhardt, K., Furr, N., Bingham, C. 2010. "Micro-foundations of Performance: Balancing Efficiency and Flexibility in Dynamic Environments.” Organizational Science, 21: 12631273.

Elekdag, S. 2008. "How Does the Global Economic Environment Influence the Demand for IMF Resources?” IMF Staff Papers 55(4): 624-653. 
Elkington, J. 2004. The Triple Bottom Line: Does it All Add Up, Routledge.

EMAS Board. 2011. "Systematic Environmental Management Creating Added Value withEMAS", available at: https://pfm.management/wp content/uploads/2014/06/Creating_Added_Value_with_EMAS_EN.pdf (accessed 22 October 2019).

EPI. 2012. "Environmental Performance Index and Pilot Trend Environmental Performance Index" available at: https://sedac.ciesin.columbia.edu/data/set/epi-environmentalperformance-index-pilot-trend-2012 (accessed 22 October 2019).

Gabzdylova, B., Raffensperger, J., and Castka, P. 2009. "Sustainability in the New Zealand Wine Industry: Drivers, Stakeholders and Practices." Journal of Cleaner Production 17(11): 992-998.

Gallo. P., and Christensen, L. 2011. "Firm Size Matters: An Empirical Investigation of Organizational Size and Ownership on Sustainability- related Behaviours.” Business \& Society 50(2): 315-349

Graafland, J., and Smid, H. 2017. "Reconsidering the Relevance of Social License Pressure and Government Regulation for Environmental Performance of European SMEs.” Journal of Cleaner Production, 141: 967-977.

Grolleau, G., Mzoughi, N., Thomas, A., 2007. "What Drives Agrifood Firms to Register for an Environmental Management System.” European Review of Agriculture Economics 34(2): $233-255$. 
Gruchmann, T and Seuring, S. 2018. "Explaining logistics social responsibility from a dynamic capabilities perspective." International Journal of Logistics Management, 29 (4): $\underline{1255-1278}$

Hall, G.M., and J. Howe. 2012. "Energy from waste and the food processing industry." Process Safety and Environmental Protection 90(3): 203-212.

Hart, S. L. and Dowell, G. 2011. “A Natural Resource-Based View of a Firm: Fifteen Years After.” Journal of Management, 37 (5): 1464-1479

Helfat, C.E. and Peteraf, M.A., 2015. "Managerial Cognitive Capabilities and the Micro Foundations of Dynamic Capabilities." Strategic Management Journal, 36(6): 831-850.

Hodgkinson, G., Healey, M. 2011. Psychological Foundations of Dynamic Capabilities: Reflexion and Reflection in Strategic Management. Strategic Management Journal. 32: $1500-1516$

ISO. 2010. ISO 9001 Certifications Top One Million Mark, Food Safety and Information security continue meteoric increase, available at: https://www.isoceltd.com/iso-9001certifications-top-one-million-mark-food-safety-and-information-security-continue-meteoricincrease (accessed 15 October 2019).

Jamali, D. Safieddine, A.M. and Rabbath, M. (2008). Corporate Governance and Corporate Social Responsibility Synergies and Interrelationships. Corporate Governance: An International Review, 16(5), 443-459.

Jormanainen, I. and Koveshnikov, A., 2012. “International Activities of Emerging Market Firms." Management International Review, 52(5): 691-725. 
Kotabe, M., Jiang, C.X. and Murray, J.Y., 2011. "Managerial Ties, Knowledge Acquisition, Realized Absorptive Capacity and New Product Market Performance of Emerging Multinational Companies: A Case of China.” Journal of World Business, 46(2): 166-176.

Kuznetsov, A. and Kuznetsova, O. 2012. "Business Legitimacy and the Margins of Corporate Social Responsibility in the Russian Context." International Studies of Management \& Organization, 42(3): 35-48.

LaBahn, D.W., and K.R. Harich. 1997. "Sensitivity to National Dynamic capabilities: Effects on U.S.-Mexican Channel Relationship Performance.” Journal of International Marketing 5(4): $29-51$

Liang, D., and Liu, T. 2017. "Does Environmental Management Capability of Chinese Industrial Firms Improve the Contribution of Corporate Environmental Performance to Economic Performance? Evidence from 2010 to 2015.” Journal of Cleaner Production, 142(4): 2985-2998.

Luo, Y., and L. Tung. 2007. "International Expansion of Emerging Market Enterprises: A Springboard Perspective.” Journal of International Business Studies, 38(4): 481-498.

MacRae, R., Szabo, M., Anderson, K., Louden, F., Trillo, S. 2012. "Empowering the CitizenConsumer: Re-Regulating Consumer Information to Support the Transition to Sustainable and Health Promoting Food Systems in Canada.” Sustainability 4(9): 2146-2175.

Marcus, A. and Anderson, M. 2006. “A General Dynamic Capability: Does it Propagate Business and Social Competencies in the Retail Food Industry." Journal of Management Studies, 43 (1): 19-46. 
Meyer, K.E. and Peng, M.W. 2016. “Theoretical Foundations of Emerging Economy Business Research.” Journal of International Business Studies, 47(1): 3-22.

Mikalef, P., and Adamantia P. 2017. "Information Technology-enabled Dynamic Capabilities and their Indirect Effect on Competitive Performance: Findings from PLS-SEM and fsQCA." Journal of Business Research. 70: 1-16.

Mollenkopf, D., Stolze, H., Tate, W.L. and Ueltschy, M. 2010. “Green, Lean, and Global Supply Chains.” International Journal of Physical Distribution \& Logistics Management, 40(1/2): 14-41.

Molina-Azorín, J. F. 2014. "Micro-foundations of Strategic Management: Toward Micromacro Research in the Resource-based theory." Business Research Quarterly, 17(2): 102114.

Naldi, L., Wikström, P. and Von Rimscha, M.B., 2014. "Dynamic Capabilities and Performance: An Empirical Study of Audiovisual Producers in Europe.” International Studies of Management \& Organization, 44(4): 63-82.

Nawrocka, D., Brorson, T. and Lindhqvist, T. 2009. "ISO 14001 in Environmental Supply Chain Practices.” Journal of Cleaner Production, 17(16): 1435-1443.

Nidumolu, R., Prahalad, K and Rangaswami, M. 2009. "Why Sustainability is now the Key Driver of Innovation." Harvard Business Review 87(9): 56-64.

Pagell, M., and Wu, Z. 2009. "Building a More Complete Theory of Sustainable Supply chain Management Using Case Studies of 10 Exemplars.” Journal of Supply Chain Management, 45(2): 37-56. 
Parboteeah, K., Helena, A., Cullen, J. 2012. "Propensity to Support Sustainability Initiatives: A Cross-National Model.” Journal of Business Ethics 105(3): 403-413.

Park, H., Russel, C., Lee, J. 2007. "National Culture and Environmental Sustainability: A Cross-national Analysis.” Journal of Economics and Finance 31(1): 104-121.

Peteraf, M., Di Stefano, G. and Verona, G., 2013. "The Elephant in the Room of Dynamic Capabilities: Bringing two Diverging Conversations Together.” Strategic Management Journal, 34(12): 1389-1410.

Pisano, G. P. 2016. Towards a Prescriptive Theory of Dynamic Capabilities: Connecting Strategic Choice, Learning, and Competition.

Porter, M. E. 1985. The Competitive Advantage: Creating and Sustaining Superior Performance. NY: Free Press.

Raţiu, P. and Mortan, M. 2014. "EMAS Implementation in SMEs: Driving Forces and Barriers." Managerial Challenges of the Contemporary Society, 7 (2): 73-79

Redclift, M. 1993. “Sustainable Development: Needs, Values, Rights.” Environmental Values 2(1): 3-20.

Redclift, M. 2005. “Sustainable Development (1987-2005): An Oxymoron Comes of Age.” Sustainable Development 13(4): 212-227.

Rugman, A.M. .1985. "Multinationals and Global Competitive Strategy.” International Studies of Management \& Organization, 15(2): 8-18. 
Saunders, C., Guenther, M., and Driver, T. 2010. "Sustainability Trends in Key Overseas Markets: Market Drivers and Implications to Increase Value for New Zealand Exports.” Research Report, Lincoln University (319): 1-49.

Sarkis, J., Zhu, Q. and Kee-hung Lai. 2011. An Organizational Theoretic Review of Green Supply Chain Management Literature. International Journal of Production Economics, 130: $1-15$

Sharma, A., Iyer, G., Mehrotra A., Krishnan, R. 2010. "Sustainability and Business-tobusiness Marketing: A Framework and Implications.” Industrial Marketing Management 39(2): 330-341.

Shaw, S., Grant, D.B., Shenin, N. and Chaisurayakarn, S. Using environmental reporting tools in the supply chain: Perspectives from UK, Finland and Thailand, Proceedings of the 21st Annual Logistics Research Network (LRN) Conference, University of Hull, September 2016, e-proceedings, ISBN 9781904564522.

Simnett , R., Vanstraelen, A., Chua, W. 2009. “Assurance on Sustainability Reports: An International Comparison.” American Accounting Association 84(3): 937-967.

Smallbone, D., Welter, F., 2001. "The Role of Government in SME Development in Transition Economies.” International Small Business Journal 19(4): 63-77.

Sölvell, Ö., \& Zander, I. 1995. “Organization of the Dynamic Multinational Enterprise: The Home-based and the Heterarchical MNE.” International Studies of Management \& Organization, 25(1-2): 17-38

Teece, D.J. 2007. "Explicating Dynamic Capabilities: The Nature and Micro-foundations of (Sustainable) Enterprise Performance.” Strategic Management Journal, 28(13): 1319-1350 
Teece, D. 2012. "Dynamics Capabilities: Routines Versus Entrepreneurial Action.” Journal of Management Studies, 49: 1395-1401.

Teece, D. J. 2014. “A Dynamic Capabilities-based Entrepreneurial Theory of the Multinational Enterprise.” Journal of International Business Studies, 45(1): 8-37.

Thompson, J. P., and Cavaleri, S. 2010. "Dynamic Knowledge, Organizational Growth, and Sustainability: The Case of Prestwick Memory Devices.” International Studies of Management \& Organization, 40(3): 50-60.

Tobler, C., V. H. M. Visschers, M. Siegrist. 2011. “Organic Tomatoes Versus Canned Beans: How do Consumers Assess the Environmental Friendliness of Vegetables?" Environment and Behaviour 43(5): 591-611.

DCVan Phan P, O’Brien M. “Multidimensional Wellbeing Inequality in a Developing Country: A Case Study of Vietnam.” Social Indicators Research. 2019,1-27.

Williamson, P. J. 2015. “The Competitive Advantages of Emerging Market Multinationals: A Re-assessment.” Critical Perspectives on International Business 11(3/4): 216-235.

Xu, D. and Meyer, K.E., 2013. "Linking Theory and Context: 'Strategy Research in Emerging Economies' after Wright et al. (2005).” Journal of Management Studies, 50(7): $1322-1346$.

Yassien, E. and Jordan, A .2015. "Big Picture of Dynamic Capabilities.” Journal of Management Research, 7 (5): 63-78. 
Zhou, K. Z., and Li. C.B. 2010. "How Strategic Orientations Influence the Building of Dynamic Capability in Emerging Economies.” Journal of Business Research, 63(3): 224231. 
Linkages between dynamic capabilities and environmental sustainability

Macro-level dynamic capabilities:

Government policies, quality indicators, legal requirements, technology and economic capability Market requirements

Economic capabilities

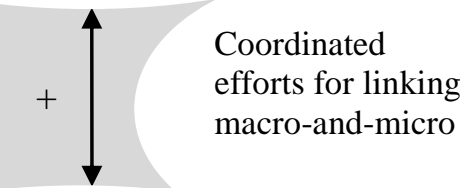

Micro-level dynamic capabilities:

Organizational size, structure \& governance, Entreprises' environmental policies Management characteristics Internal coordination efforts

\section{.}

